\title{
Nickel Germanide Thin Films by Atomic Layer Deposition
}

\section{Väyrynen, Katja}

2019-07-23

Väyrynen , K, Vihervaara , A , Hatanpää , T, Mattinen , M , Heikkilä , M J , Mizohata , K, Raisanen , J , Ritala , M \& Leskelä , M 2019 , ' Nickel Germanide Thin Films by Atomic Layer Deposition ' , Chemistry of Materials , vol. 31 , no. 14 , pp. 5314-5319 . https://doi.org/10.1021/acs.chemmater

http://hdl.handle.net/10138/304806

https://doi.org/10.1021/acs.chemmater.9b01877

cc_by

publishedVersion

Downloaded from Helda, University of Helsinki institutional repository.

This is an electronic reprint of the original article.

This reprint may differ from the original in pagination and typographic detail.

Please cite the original version. 


\title{
Nickel Germanide Thin Films by Atomic Layer Deposition
}

\author{
Katja Väyrynen, ${ }^{\dagger}$ Anton Vihervaara, ${ }^{\dagger}$ Timo Hatanpää, ${ }^{\dagger}$ Miika Mattinen, ${ }^{\dagger}$ Mikko J. Heikkilä, \\ Kenichiro Mizohata, Jyrki Räisänen, ${ }^{\ddagger}$ Mikko Ritala, ${ }^{* \dagger}{ }^{\dagger}$ and Markku Leskelä ${ }^{\dagger}$
}

${ }^{\dagger}$ Department of Chemistry, University of Helsinki, P.O. Box 55, FI-00014 Helsinki, Finland

${ }^{\ddagger}$ Department of Physics, University of Helsinki, P.O. Box 43, FI-00014 Helsinki, Finland

\author{
Supporting Information
}

\begin{abstract}
This work presents preparation of nickel germanide $\left(\mathrm{Ni}_{2} \mathrm{Ge}\right)$ thin films by atomic layer deposition (ALD). The films were grown using $\mathrm{NiCl}_{2}$ (tmpda) (tmpda $=N, N, N^{\prime}, N^{\prime}$,-tetramethyl-1,3-propanediamine) and tributylgermanium hydride serving as a new, efficient reducing agent. This is the first time ALD $\mathrm{Ni}_{x} \mathrm{Ge}_{y}$ films are prepared directly upon the combination of two precursors and without any annealing treatment. $\mathrm{Ni}_{x} \mathrm{Ge}_{y}$ is an important contact material for enabling Ge-based transistors and thus circumventing the scaling issues related to current microelectronics. The $\mathrm{Ni}_{2} \mathrm{Ge}$ process was examined at low temperatures of $160-200{ }^{\circ} \mathrm{C}$. Self-limiting, saturative growth with a high growth rate of $0.91 \AA$ / cycle was observed at $180{ }^{\circ} \mathrm{C}$. The films were thoroughly analyzed in terms of morphology, crystallinity, composition, and resistivity. The $\mathrm{Ni}_{2} \mathrm{Ge}$ films were pure, with the sum of contaminants being less than 1 at. \%. Owing to their high purity, the films exhibited low resistivity, suggesting suitability for contact applications.
\end{abstract}

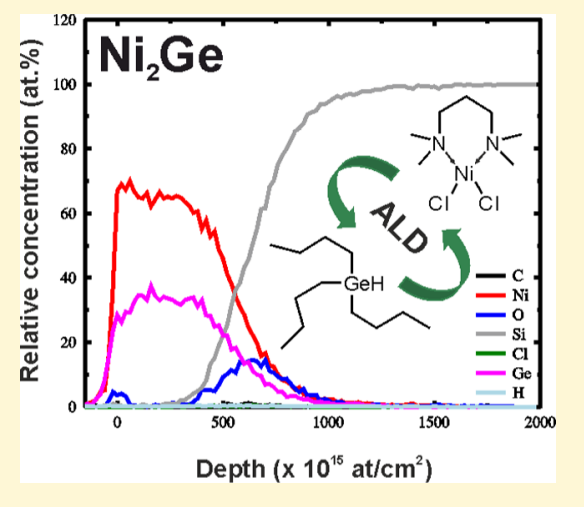

\section{INTRODUCTION}

Ge was the material of choice for the early transistors in the 1950s, but has since been replaced by $\mathrm{Si}$ for its high-quality native oxide $\left(\mathrm{SiO}_{2}\right)$. With $\mathrm{Si}$ reaching its limits in terms of scaling down and the gate $\mathrm{SiO}_{2}$ being replaced by high- $\kappa$ oxides, alternatives to the Si-based technology are being actively investigated. Ge is making a strong comeback, bringing the transistor technology full circle. ${ }^{1,2}$ Ge exhibits high carrier mobility and compatibility with $\mathrm{Si}$ processing, making it a promising candidate for developing next-generation, highperformance devices.

Exploiting the benefits of the Ge-based technology requires low-resistance contacts. Metal germanides are the most logical option, being equivalent to $\mathrm{TiSi}_{2}, \mathrm{CoSi}_{2}$, and $\mathrm{NiSi}$ employed in $\mathrm{Si}$ devices. ${ }^{3,4}$ Owing to its low resistivity, nickel germanide is one of the most prominent candidates for contacting Ge. $\mathrm{Ni}_{x} \mathrm{Ge}_{y}$ films are typically prepared by annealing physical vapor-deposited (PVD) Ni metal films on Ge substrates. ${ }^{5-12}$ Atomic layer deposition (ALD) provides superior accuracy and conformality to the PVD techniques and thus enables scaling down with three-dimensional (3D) designs and sub-10 nm thin films. ${ }^{13-15}$ There are no reports of processes involving direct ALD of metal germanides. The ALD route to NiGe has previously been realized only by heating ALD Ni or NiO films on Ge to temperatures above $400{ }^{\circ} \mathrm{C} .{ }^{16,17}$

Diamine adducts of metal(II) halides are known compounds ${ }^{18,19}$ but have only recently been studied for their volatility and established as suitable ALD precursors. $\mathrm{NiCl}_{2}$ (tmpda) has been used to deposit $\mathrm{Ni}_{3} \mathrm{Sn}_{2}$ and $\mathrm{Ni}_{3} \mathrm{~N}$ thin films by $\mathrm{ALD} .^{20,21} \mathrm{~A}$ cobalt analogue with a slightly different amine ligand resulted in being useful for the ALD of
$\mathrm{CoO}$ and $\mathrm{Co}_{3} \mathrm{Sn}_{2}$ films. ${ }^{20,22}$ What is common to all these processes is that the films are essentially free from impurities, indicating efficient ligand removal and complete reactions. The precursors are inexpensive and easy to synthesize, making them readily applicable also for industrial purposes.

Hydrides have recently emerged as alternative reducing agents for developing new ALD processes: first, to deposit $\mathrm{Al}$ metal, and second, for the ALD of $\mathrm{Co}_{3} \mathrm{Sn}_{2}$ and $\mathrm{Ni}_{3} \mathrm{Sn}_{2}$ films. ${ }^{20,23}$ According to density functional theory calculations, $\mathrm{Cu}(\mathrm{I})$ carbene hydrides may act as both the metal compound and the reducing agent for $\mathrm{Cu}$ ALD. ${ }^{24}$ Hydrides have proven to be efficient reducing agents but involve complex chemistry not yet thoroughly understood. Further work on this intriguing group of reactants is required to harness their full potential and expand the materials selection available by ALD.

Herein, we introduce the first direct ALD process for $\mathrm{Ni}_{x} \mathrm{Ge}_{y}$ thin films using tributylgermanium hydride (TBGH) as the reducing agent. The schematic structures of the precursors employed in this study are illustrated in Figure 1. The deposition of high-quality films under saturated conditions at low temperatures below $200{ }^{\circ} \mathrm{C}$ is demonstrated. The process

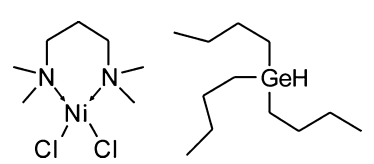

Figure 1. Schematic structures of $\mathrm{NiCl}_{2}$ (tmpda) and $\mathrm{TBGH}$.

Received: May 13, 2019

Revised: June 19, 2019

Published: June 27, 2019 
a)

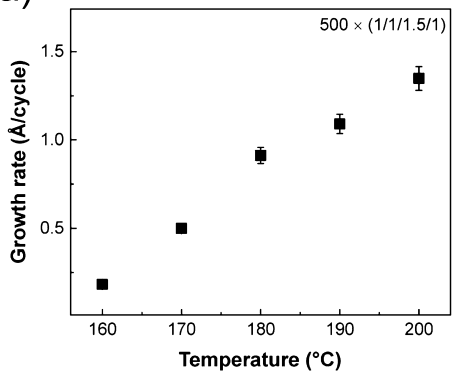

c)

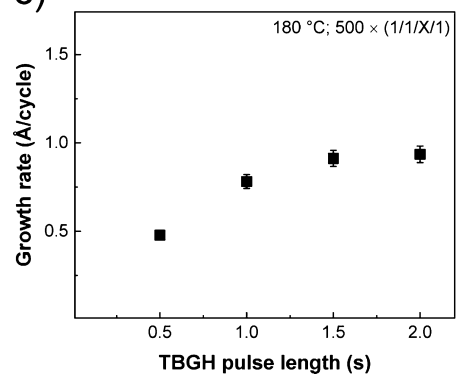

b)

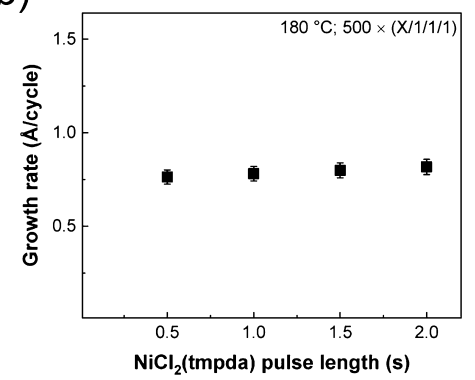

d)

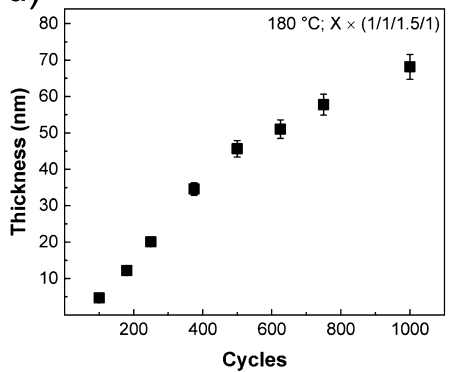

e)

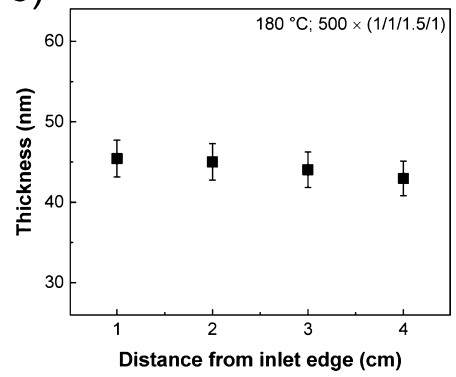

Figure 2. Growth characteristics of the $\mathrm{Ni}_{2} \mathrm{Ge}$ process on $\mathrm{Al}_{2} \mathrm{O}_{3}$ : growth rate with respect to (a) temperature, (b) Ni precursor, and (c) TBGH pulse length. Film thickness as a function of (d) the number of deposition cycles and (e) position on the substrate.

provides an important pathway for developing Ge-based transistors. Furthermore, the results give valuable information on the emerging topic of hydride reducing agent, possibly enabling ALD of other germanides, pure metals, or even elemental Ge.

\section{EXPERIMENTAL SECTION}

Film Deposition. All films were grown in a hot-wall, cross-flow F120 ALD reactor provided by ASM Microchemistry. Nitrogen (AGA, 99.999\%; $\left.\mathrm{H}_{2} \mathrm{O}, \leq 3 \mathrm{ppm} ; \mathrm{O}_{2}, \leq 3 \mathrm{ppm}\right)$ was used as the carrier and purge gas. The reactor pressure was $\sim 10$ mbar. $\mathrm{NiCl}_{2}$ (tmpda) was synthesized in-house according to the procedure reported in our previous publication. ${ }^{20}$ TBGH was purchased from both Gelest and Sigma-Aldrich. Both precursors were evaporated from open glass boats held inside the reactor. The evaporation temperatures for $\mathrm{NiCl}_{2}$ (tmpda) and $\mathrm{TBGH}$ were 157 and $30{ }^{\circ} \mathrm{C} . \mathrm{Ni}_{2} \mathrm{Ge}$ films were deposited on native oxide-terminated $\mathrm{Si}(100)$ and soda lime glass substrates coated with $10 \mathrm{~nm} \mathrm{Al} \mathrm{O}_{3}\left(\mathrm{AlMe}_{3}+\right.$ water) prior to deposition. $\mathrm{The} \mathrm{Al}_{2} \mathrm{O}_{3}$ film was required for promoting nucleation on the glass substrate. Film growth was examined also on Ge substrates. The Ge substrates were precleaned with $10 \% \mathrm{HCl}$ for $2 \mathrm{~min}$, rinsed with deionized water, and treated with a pulse of $\mathrm{AlMe}_{3}$ prior to $\mathrm{Ni}_{2} \mathrm{Ge}$ deposition.

Film Characterization. Film thicknesses were determined by energy-dispersive X-ray spectrometry (EDS), employing an Oxford INCA 350 microanalysis system connected to a Hitachi S-4800 scanning electron microscope. The thicknesses were quantified from $\mathrm{Ni} \mathrm{K} \alpha$ and Ge K $\alpha$ X-ray lines using the GMRFILM program. The film density was approximated at $8.88 \mathrm{~g} / \mathrm{cm}^{3}$. Each result was treated with an uncertainty of $5 \%$.

Film morphology was assessed by scanning electron microscopy (SEM) imaging. Further analysis was done by atomic force microscopy (AFM, Veeco Multimode V instrument). The images were captured in air using $\mathrm{Si}$ probes with a nominal tip radius of 10 $\mathrm{nm}$ and a spring constant of $5 \mathrm{~N} / \mathrm{m}$ (Tap150 from Bruker). The images were flattened to remove artifacts from the sample tilt and scanner bow. Roughness was calculated as a root-mean-square value $\left(R_{\mathrm{q}}\right)$.

The films were identified by X-ray diffraction (XRD) using a PANalytical X'Pert Pro MPD X-ray diffractometer. The measurements were done with parallel beam optics and grazing incidence geometry. The $\mathrm{Cu} K \alpha(\lambda=1.54)$ incident angle was $1^{\circ}$. Hightemperature XRD (HTXRD) measurements were carried out under $\mathrm{N}_{2}$ in an Anton-Paar HTK1200 oven connected to the X-ray diffractometer. Time-of-flight elastic recoil detection analysis (ToFERDA) was utilized for determining the film composition. A $40 \mathrm{MeV}$ ${ }^{127} \mathrm{I}^{7+}$ ion beam was used for probing the sample. Film resistivity was evaluated with a four-point probe (CPS Probe Station, Cascade Microtech and a Keithley 2400 SourceMeter). Sheet resistances were measured on $\mathrm{Al}_{2} \mathrm{O}_{3}$-coated glass substrates and multiplied by film thicknesses to acquire resistivities.

\section{RESULTS}

Precursor Properties. $\mathrm{NiCl}_{2}$ (tmpda), a diamine adduct of $\mathrm{Ni}(\mathrm{II})$ chloride, has proven to be suitable for depositing $\mathrm{Ni}_{3} \mathrm{Sn}_{2}$ and $\mathrm{Ni}_{3} \mathrm{~N}$ thin films by ALD. ${ }^{20,21}$ The precursor was selected also for this study because of the high reactivity of the chloride ligands toward hydride reducing agents. $\mathrm{NiCl}_{2}$ (tmpda) is a solid compound that can be sublimed quantitatively under vacuum at $157^{\circ} \mathrm{C}$. The precursor decomposes at temperatures above $250{ }^{\circ} \mathrm{C}^{21} \mathrm{NiCl}_{2}$ (tmpda) can be prepared from inexpensive starting materials with a high yield and is thus a good ALD precursor also from an industrial point of view. The compound is synthesized simply by mixing $\mathrm{NiCl}_{2}$ solution with a threefold excess of the amine and refluxing for $3 \mathrm{~h}$. A more detailed description of the synthesis can be found in the literature. ${ }^{20}$

TBGH is the Ge analogue of tributyltin hydride (TBTH) that has previously been used for the ALD of intermetallic $\mathrm{Co}_{3} \mathrm{Sn}_{2}$ and $\mathrm{Ni}_{3} \mathrm{Sn}_{2}$ thin films. ${ }^{20}$ A suitable evaporation temperature for $\mathrm{TBGH}\left(30^{\circ} \mathrm{C}\right)$ was empirically found based on the earlier experience with TBTH. The advantages of using Ge alkyl hydrides instead of their Sn equivalents include low toxicity and good stability. ${ }^{25}$ Because of the similarity of the Ge and $\mathrm{Sn}$ alkyl hydrides, we believe that the $\mathrm{Ni}_{2} \mathrm{Ge}$ process proceeds through a similar reaction mechanism (eq 1 ) as was previously proposed for $\mathrm{Co}_{3} \mathrm{Sn}_{2}$ and $\mathrm{Ni}_{3} \mathrm{Sn}_{2} \cdot{ }^{20}$ Most likely, the butyl groups of TBGH react with the chloride ligands on the surface and form volatile chlorobutane and $\mathrm{HCl}$ as by- 

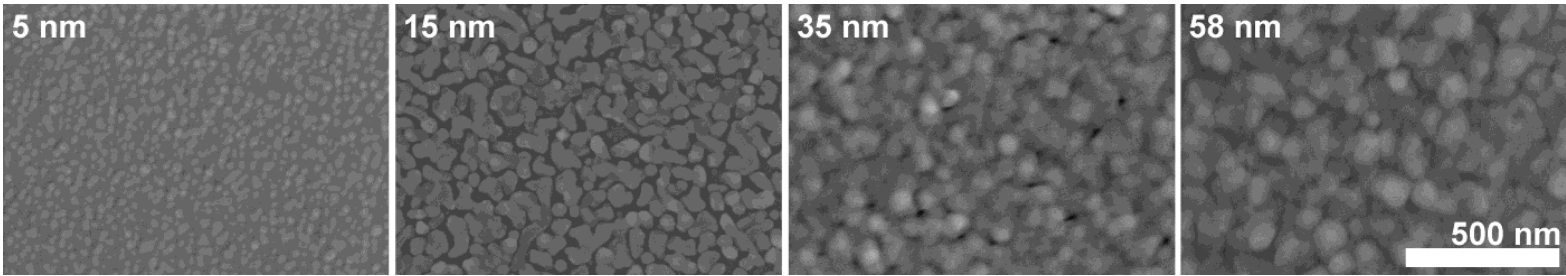

Figure 3. Nucleation and morphology evolution of $\mathrm{Ni}_{2} \mathrm{Ge}$ films deposited on $\mathrm{Al}_{2} \mathrm{O}_{3}$ at $180{ }^{\circ} \mathrm{C}$.

products. The neutral adduct ligand tmpda is eliminated simply by dissociation. In situ mechanistic studies on these processes are underway and will be published separately.

$$
\begin{aligned}
& 2 \mathrm{NiCl}_{2}(\text { tmpda })+\mathrm{Bu}_{3} \mathrm{GeH} \\
& \quad \rightarrow \mathrm{Ni}_{2} \mathrm{Ge}+3 \mathrm{BuCl}+\mathrm{HCl}+\text { tmpda }
\end{aligned}
$$

Growth Characteristics. Figure 2 provides the results regarding the growth characteristics of the $\mathrm{Ni}_{2} \mathrm{Ge}$ ALD process. The films were deposited at low temperatures of $160-200{ }^{\circ} \mathrm{C}$, and the growth rate increased with increasing temperature (Figure 2a). The growth rate increased from $0.18 \AA$ /cycle at $160{ }^{\circ} \mathrm{C}$ to $1.3 \AA /$ cycle at $200{ }^{\circ} \mathrm{C}$. The lowest applicable deposition temperature was dictated by the sublimation temperature of the $\mathrm{Ni}$ precursor $\left(157^{\circ} \mathrm{C}\right)$. At $200{ }^{\circ} \mathrm{C}$, the film did not extend to the exhaust edge of the substrate. This may indicate the decomposition of $\mathrm{TBGH}$, as we have previously shown that $\mathrm{NiCl}_{2}$ (tmpda) starts to decompose only at temperatures above $250{ }^{\circ} \mathrm{C}$. ${ }^{21}$ Another possibility is that the film is etched by the by-product $\mathrm{HCl}$ and the free tmpda ligands or that these start to block the surface sites from the precursor molecules. It is also possible that the precursor doses were insufficient for the highest growth rate so that the precursors were consumed before reaching the outlet edge of the substrate.

The self-limiting growth mechanism of the process was examined at $180{ }^{\circ} \mathrm{C}$. Saturative growth was verified with respect to both precursors. A short pulse of only $0.5 \mathrm{~s}$ was enough to observe saturation as a function of the Ni precursor pulse time (Figure $2 \mathrm{~b}$ ). A longer pulse of $1.5 \mathrm{~s}$ was required for reaching saturation with TBGH (Figure 2c). Under fully saturated conditions, a high growth rate of $0.91 \AA$ /cycle was observed. Saturation with respect to the $\mathrm{Ni}$ precursor was studied using $1.0 \mathrm{~s}$ TBGH pulses but was also verified with 1.5 s TBGH pulses. A lower growth rate of $0.76 \AA$ /cycle was measured when the purge times were doubled, suggesting a minor chemical vapor deposition component or desorption of the precursors.

Figure $2 \mathrm{~d}$ shows the relationship between film thickness and cycle count. Two linear regions were observed instead of the expected one. Apart from a short nucleation delay, the film thickness increased linearly within the first 500 cycles with a rate of $0.91 \AA$ /cycle. After the first 500 cycles, the film thickness still increased linearly but with a lower growth rate of $0.45 \AA /$ cycle. The reason for the change in the growth rate can be ascribed to reaching full coverage of the initial substrate surface after 500 cycles; the film-forming reactions appear to be more facile on $\mathrm{Al}_{2} \mathrm{O}_{3}$ than on the film itself. Initially, the $\mathrm{Al}_{2} \mathrm{O}_{3}$ surface is covered by $-\mathrm{OH}$ groups that serve as reactive sites for the precursors. After the $-\mathrm{OH}$ groups have been consumed from the $\mathrm{Al}_{2} \mathrm{O}_{3}$ surface, it has coordinatively unsaturated $\mathrm{Al}$ and $\mathrm{O}$ ions that can also serve as reactive sites for the film growth reactions. The agglomeration of the film material ensures that $\mathrm{Al}_{2} \mathrm{O}_{3}$ remains partly uncovered up to a relatively high number of deposition cycles, that is, high film thickness (see below). A similar observation has been made in the case of $\mathrm{Cu}$ ALD. ${ }^{26,27}$

The $\mathrm{Ni}_{2} \mathrm{Ge}$ films exhibited excellent thickness uniformity across the $5 \mathrm{~cm} \times 5 \mathrm{~cm}$ substrates, as demonstrated by Figure 2e. Good uniformity was observed also in the case of $\mathrm{Co}_{3} \mathrm{Sn}_{2}$ films. $^{20}$

Film Properties. The morphology of all the films was evaluated by SEM. Film nucleation is visualized in Figure 3 showing the SEM images of films of different thicknesses deposited at $180{ }^{\circ} \mathrm{C}$. Thin yet continuous films are obtained when agglomeration and grain growth are minimized, that is, at low temperatures and with high growth rates. ${ }^{28-30}$ Despite the low deposition temperature and high growth rate, the thinnest film of $5 \mathrm{~nm}$ consisted of separate islands and was nonconductive. The substrate coverage was improved with increasing cycle count, but some holes are still visible in the 35 $\mathrm{nm}$ thick $\mathrm{Ni}_{2} \mathrm{Ge}$ film. Although not covering the substrate fully, the $15 \mathrm{~nm}$ thick film forms a continuous network across the substrate and is conductive. The grain size increased with increasing cycle count and consequently increasing film thickness.

The film morphology was further analyzed by AFM (Figure 4). All the films were rough, with the respective $R_{\mathrm{q}}$ values being

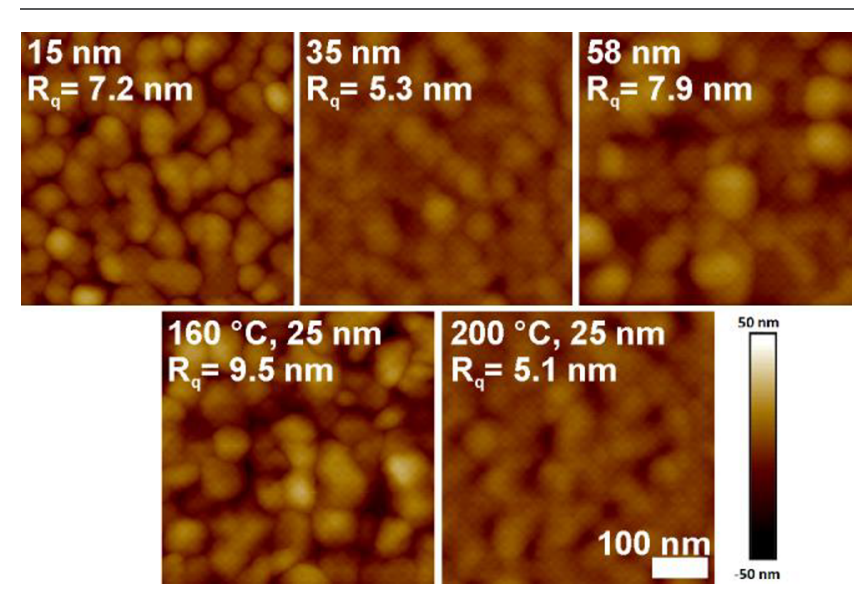

Figure 4. AFM images of films of different thicknesses deposited on $\mathrm{Al}_{2} \mathrm{O}_{3}$ at $180{ }^{\circ} \mathrm{C}$ and of $25 \mathrm{~nm}$ films deposited at 160 and $200{ }^{\circ} \mathrm{C}$.

7.2, 5.3, and $7.9 \mathrm{~nm}$ for 15,35 , and $58 \mathrm{~nm}$ thick $\mathrm{Ni}_{2}$ Ge films deposited at $180^{\circ} \mathrm{C}$. Because of the discontinuity, the thinnest film was rougher than the $35 \mathrm{~nm}$ thick film. Expectedly, the roughness increased with increasing film thickness after the substrate was first fully covered. Figure 4 also compares the roughnesses of $25 \mathrm{~nm}$ thick films deposited at 160 and $200{ }^{\circ} \mathrm{C}$. The film deposited at $200{ }^{\circ} \mathrm{C}$ was significantly smoother than the film deposited at $160{ }^{\circ} \mathrm{C}$. The $R_{\mathrm{q}}$ values for the films were 5.1 and $9.5 \mathrm{~nm}$. The 3D images of all the films are shown in 
Figure S1, Supporting Information. In the case of $\mathrm{Ni}_{2} \mathrm{Ge}$, high growth rate is more important for obtaining smooth films than low temperature. The growth rate was significantly higher at $200{ }^{\circ} \mathrm{C}$ as opposed to $160{ }^{\circ} \mathrm{C}(1.3$ vs $0.18 \AA$ /cycle $)$. With high growth rates, the nuclei have less time for grain growth, which promotes the formation of smooth films. Smooth films generally have better electrical properties because of less electron-scattering effects. ${ }^{31}$

All the films were analyzed by XRD. Figure 5 shows an exemplary X-ray diffractogram of a $46 \mathrm{~nm}$ thick $\mathrm{Ni}_{2} \mathrm{Ge}$ film

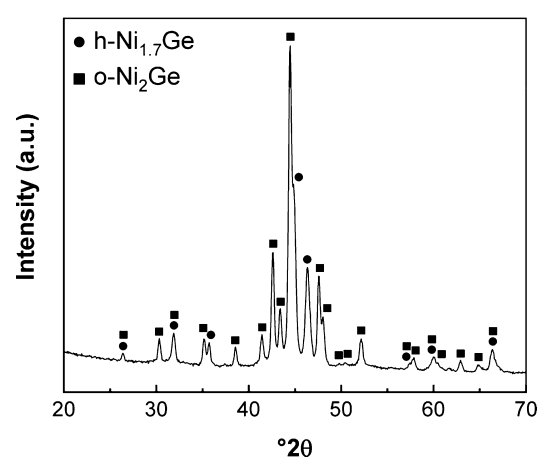

Figure 5. Grazing incidence X-ray diffractogram of a $46 \mathrm{~nm}$ thick $\mathrm{Ni}_{2} \mathrm{Ge}$ film grown on $\mathrm{Al}_{2} \mathrm{O}_{3}$ at $180{ }^{\circ} \mathrm{C}$.

deposited at $180^{\circ} \mathrm{C}$. The film was highly crystalline, consisting mainly of two phases: the orthorhombic $\mathrm{Ni}_{2} \mathrm{Ge}$ and the slightly $\mathrm{Ni}$ deficient hexagonal $\mathrm{Ni}_{1.7} \mathrm{Ge}$ phase. The $\mathrm{NiGe}$ phase was not observed. The films were crystalline within the entire temperature range $\left(160-200{ }^{\circ} \mathrm{C}\right)$ and at all thicknesses (5$70 \mathrm{~nm}$ ). Apart from the temperature, the growth parameters had no significant effect on the crystallinity. Expectedly, the crystallinity was enhanced when the films were grown at higher temperatures or with more cycles. To study the behavior of the films at higher temperatures, like those encountered in subsequent steps in semiconductor processing, the films were subjected to HTXRD measurements under $\mathrm{N}_{2}$. Upon heating in HTXRD, the orthorhombic $\mathrm{Ni}_{2} \mathrm{Ge}$ started to convert to the hexagonal $\mathrm{Ni}_{2} \mathrm{Ge}$ phase at $500{ }^{\circ} \mathrm{C}$, and at $600{ }^{\circ} \mathrm{C}$, only the hexagonal phase was left.

The film composition was examined by ToF-ERDA. Figure 6 depicts the representative elemental depth profiles of a 60 $\mathrm{nm}$ thick $\mathrm{Ni}_{2} \mathrm{Ge}$ film grown at $180^{\circ} \mathrm{C}$. The $\mathrm{Ni}$ and $\mathrm{Ge}$ contents

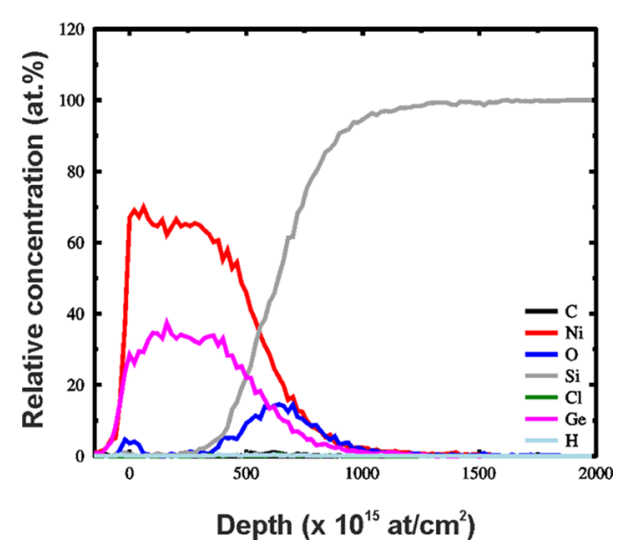

Figure 6. Elemental depth profiles of a $60 \mathrm{~nm}$ thick $\mathrm{Ni}_{2} \mathrm{Ge}$ film deposited on $\mathrm{Al}_{2} \mathrm{O}_{3}$ at $180{ }^{\circ} \mathrm{C}$. No nitrogen was detected in the film. in the film were 65 and 34 at. \%. The stoichiometry correlates well with the XRD results. Similar results were also seen by EDS. Apart from slight surface oxidation, the film was of high purity, and the total contaminant level was less than 1 at. \%. Despite being a ligand of the $\mathrm{Ni}$ precursor, the $\mathrm{Cl}$ content was as low as 0.06 at. \%. The nitrogen content was below the detection limit (0.07 at. \%) of the ToF-ERDA instrument. Previous studies using the diamine adducts of $\mathrm{Co}(\mathrm{II})$ and $\mathrm{Ni}$ (II) chlorides as ALD precursors have all produced films with high purity. ${ }^{20-22}$ It can be concluded that these precursors undergo fast and complete reactions when combined with suitable reactants.

Film resistivities were assessed by four-point probe measurements. A $15 \mathrm{~nm}$ thick $\mathrm{Ni}_{2} \mathrm{Ge}$ film deposited at $180{ }^{\circ} \mathrm{C}$ formed a continuous network across the substrate but still exhibited a high resistivity of $450 \mu \Omega \mathrm{cm}$. At a thickness of $24 \mathrm{~nm}$, the resistivity was decreased to $50 \mu \Omega \mathrm{cm}$. When deposited at 160 ${ }^{\circ} \mathrm{C}$, a film thickness of only $9 \mathrm{~nm}$ was enough for obtaining conductive films, albeit with a high resistivity of $470 \mu \Omega \mathrm{cm}$. At the lowest, a resistivity of only $26 \mu \Omega \mathrm{cm}$ was obtained for a 68 $\mathrm{nm}$ thick film grown at $180{ }^{\circ} \mathrm{C}$. This result is well in line with the existing literature on $\mathrm{Ni}_{x} \mathrm{Ge}_{y}$ films prepared by annealing $\mathrm{Ni}$ films on Ge substrates. The lowest values reported for $\mathrm{Ni}_{x} \mathrm{Ge}_{y}$ vary between 17 and $24 \mu \Omega \mathrm{cm}$. ${ }^{5,6,17}$ The resistivity of $\mathrm{Ni}_{x} \mathrm{Ge}_{y}$ is phase-dependent; the $\mathrm{Ni}_{2} \mathrm{Ge}$ and $\mathrm{Ni}_{5} \mathrm{Ge}_{3}$ phases exhibit a slightly higher resistivity than the NiGe phase. ${ }^{6}$ The $1: 1$ stoichiometry is typically obtained by high-temperature annealing of $\mathrm{Ni}$ or $\mathrm{NiO}$ films on $\mathrm{Ge}$ substrates, that is, only when there is excess $\mathrm{Ge}$ available.

As a proof of concept, we showed that $\mathrm{Ni}_{2} \mathrm{Ge}$ films can also be deposited on Ge substrates. The native oxide was removed by $\mathrm{HCl}$ treatment and a pulse of $\mathrm{AlMe}_{3}$ prior to deposition. A film with $11 \mathrm{~nm}$ thickness was obtained from 500 cycles at 180 ${ }^{\circ} \mathrm{C}$, adding up to a growth rate of $0.22 \AA /$ cycle. The $\mathrm{Ni}_{2} \mathrm{Ge}$ film on Ge was only weakly crystalline, as shown by XRD. AFM showed that the film consisted of a smooth layer and some scattered 10-50 nm high unknown particles (Figure S2 in the Supporting Information). The $R_{\mathrm{q}}$ value was $3.2 \mathrm{~nm}$ without and $9.8 \mathrm{~nm}$ with the particles. The $R_{\mathrm{q}}$ value of the Ge substrate was $1.4 \mathrm{~nm}$. The resistivity measurement was somewhat complicated because of the conductivity of the Ge substrate. The sheet resistance was, however, decreased significantly by the $\mathrm{Ni}_{2} \mathrm{Ge}$ deposition; the sheet resistance of the bare substrate was $1.6 \mathrm{k} \Omega / \square$ and that of the film-substrate combination was $4.5 \Omega / \square$. From the sheet resistance of $4.5 \Omega / \square$, a resistivity of $22 \mu \Omega \mathrm{cm}$ can be calculated for the $11 \mathrm{~nm}$ thick $\mathrm{Ni}_{2} \mathrm{Ge}$ film. Further work is required to study the contact resistance of the system and integrate the process to actual device structures.

\section{CONCLUSIONS}

This article presented the ALD of $\mathrm{Ni}_{2} \mathrm{Ge}$ thin films directly by combining two precursors at low temperatures. $\mathrm{NiCl}_{2}$ (tmpda) has proven to be a suitable precursor for many $\mathrm{Ni}$-containing materials and is also inexpensive and easy to synthesize with a high yield. This work introduced a new reducing agent, TBGH, for the ALD of metal germanides. Future work will show whether TBGH is also suitable for depositing pure metals and elemental Ge. The $\mathrm{Ni}_{2} \mathrm{Ge}$ films were grown at $160-200{ }^{\circ} \mathrm{C}$. The saturation of the growth rate $(0.91 \AA /$ cycle $)$ was verified with respect to both precursors at $180{ }^{\circ} \mathrm{C}$. A thorough analysis in terms of growth characteristics, morphology, crystallinity, composition, and electrical properties was carried out. The films were of very high purity and, consequently, exhibited low 
resistivity values. As a proof of concept, we demonstrated that the films could be deposited also on Ge substrates. The good electrical conductivity of the $\mathrm{Ni}_{2} \mathrm{Ge}$ films suggests applicability for contact applications in Ge-based transistors. The process shown here provides an important pathway for creating solutions to the scaling issues of the current Si-based technology.

\section{ASSOCIATED CONTENT}

\section{S Supporting Information}

The Supporting Information is available free of charge on the ACS Publications website at DOI: 10.1021/acs.chemmater.9b01877.

\section{Additional AFM data (PDF)}

\section{AUTHOR INFORMATION}

\section{Corresponding Author}

*E-mail: mikko.ritala@helsinki.fi.

\section{ORCID $\odot$}

Katja Väyrynen: 0000-0002-8886-6997

Timo Hatanpää: 0000-0003-3745-8296

Miika Mattinen: 0000-0003-4837-1823

Mikko Ritala: 0000-0002-6210-2980

Markku Leskelä: 0000-0001-5830-2800

\section{Author Contributions}

All authors have given approval to the final version of the manuscript.

\section{Notes}

The authors declare no competing financial interest.

\section{ACKNOWLEDGMENTS}

ASM Microchemistry Oy is gratefully acknowledged for funding this research.

\section{REFERENCES}

(1) Brunco, D. P.; De Jaeger, B.; Eneman, D.; Satta, A.; Terzieva, V.; Souriau, L.; Leys, F. E.; Pourtois, G.; Houssa, M.; Opsomer, K.; Nicholas, G.; Meuris, M.; Heyns, M. M. Germanium: The Past and Possibly a Future Material for Microelectronics. ECS Trans. 2007, 11, 479-493.

(2) Goley, P.; Hudait, M. Germanium Based Field-Effect Transistors: Challenges and Opportunities. Materials 2014, 7, 2301-2339.

(3) Kittl, J. A.; Lauwers, A.; Chamirian, O.; Van Dal, M.; Akheyar, A.; De Potter, M.; Lindsay, R.; Maex, K. Ni- and Co-Based Silicides for Advanced CMOS Applications. Microelectron. Eng. 2003, 70, 158165.

(4) Zhang, S.-L.; Östling, M. Metal Silicides in CMOS Technology: Past, Present, and Future Trends. Crit. Rev. Solid State Mater. Sci. 2003, 28, 1-129.

(5) Spann, J. Y.; Anderson, R. A.; Thornton, T. J.; Harris, G.; Thomas, S. G.; Tracy, C. Characterization of Nickel Germanide Thin Films for Use as Contacts to p-Channel Germanium MOSFETs. IEEE Electron Device Lett. 2005, 26, 151-153.

(6) Gaudet, S.; Detavernier, C.; Kellock, A. J.; Desjardins, P.; Lavoie, C. Thin Film Reaction of Transition Metals with Germanium. J. Vac. Sci. Technol., A 2006, 24, 474-485.

(7) Brunco, D. P.; Opsomer, K.; De Jaeger, B.; Winderickx, G.; Verheyden, K.; Meuris, M. Observation and Suppression of Nickel Germanide Overgrowth on Germanium Substrates with Patterned $\mathrm{SiO}_{2}$ Structures. Electrochem. Solid-State Lett. 2007, 11, H39-H41.

(8) Kang, M.-H.; Shin, H.-S.; Yoo, J.-H.; Lee, G.-W.; Oh, J.-W.; Majhi, P.; Jammy, R.; Lee, H.-D. Thermally Robust Ni Germanide
Technology using Cosputtering of $\mathrm{Ni}$ and $\mathrm{Pt}$ for High-Performance Nanoscale Ge MOSFETs. IEEE Trans. Nanotechnol. 2012, 11, 769776.

(9) De Schutter, B.; van Stiphout, K.; Santos, N. M.; Bladt, E.; Jordan-Sweet, J.; Bals, S.; Lavoie, C.; Comrie, C. M.; Vantomme, A.; Detavernier, C. Phase Formation and Texture of Thin Nickel Germanides on $\mathrm{Ge}(001)$ and $\mathrm{Ge}(111)$. J. Appl. Phys. 2016, 119, 135305.

(10) van Stiphout, K.; Geenen, F. A.; De Schutter, B.; Santos, N. M.; Miranda, S. M. C.; Joly, V.; Detavernier, C.; Pereira, L. M. C.; Temst, K.; Vantomme, A. Formation of Ultrathin Ni Germanides: SolidPhase Reaction, Morphology and Texture. J. Phys. D: Appl. Phys. 2017, 50, 455301.

(11) Jablonka, L.; Kubart, T.; Gustavsson, F.; Descoins, M.; Mangelinck, D.; Zhang, S.-L.; Zhang, Z. Improving the Morphological Stability of Nickel Germanide by Tantalum and Tungsten Additions. Appl. Phys. Lett. 2018, 112, 103102.

(12) Deng, Y.; He, D.; Qiu, Y.; Gu, R.; He, J.; Nakatsuka, O. Impact of Crystalline Structures on the Thermal Stability and Schottky Barrier Height of NiGe/Ge Contact. Appl. Phys. Lett. 2018, 113, 253503.

(13) Leskelä, M.; Ritala, M. Atomic Layer Deposition (ALD): From Precursors to Thin Film Structures. Thin Solid Films 2002, 409, 138146.

(14) Ritala, M.; Niinistö, J. Atomic Layer Deposition. In Chemical Vapour Deposition: Precursors, Processes and Applications; Jones, A. C., Hitchman, M. L., Eds.; Royal Society of Chemistry: Cambridge, U.K., 2009; Chapter 4, pp 158-206.

(15) George, S. M. Atomic Layer Deposition: An Overview. Chem. Rev. 2010, 110, 111-131.

(16) Pore, V. J.; Haukka, S. P.; Blomberg, T. E.; Tois, E. E. Methods for Depositing Nickel Films and for Making Nickel Silicide and Nickel Germanide. U.S. Patent 9,379,011 B2, June 28, 2016.

(17) Ahn, H. J.; Moon, J.; Seo, Y.; Lee, T. I.; Kim, C.-K.; Hwang, W. S.; Yu, H.-Y.; Cho, B. J. Formation of Low-Resistivity Nickel Germanide using Atomic Layer Deposited Nickel Thin Film. IEEE Trans. Electron Devices 2017, 64, 2599-2603.

(18) Handley, D. A.; Hitchcock, P. B.; Lee, T. H.; Leigh, G. J. Complexes of Metal(II) Halides of the First Transition Series with $\mathrm{N}, \mathrm{N}, \mathrm{N}^{\prime}, \mathrm{N}^{\prime}$-Tetramethylmethane-diamine, -ethane-1,2-diamine and -propane-1,3-diamine. Inorg. Chim. Acta 2001, 314, 14-21.

(19) Handley, D. A.; Hitchcock, P. B.; Leigh, G. J. Triangulopentahalotrimetal Complexes of Nickel(II) and Cobalt(II) with $\mathrm{N}, \mathrm{N}, \mathrm{N}^{\prime} \mathrm{N}^{\prime}$,-Tetramethylethane-1,2-diamine and Related Compounds. Inorg. Chim. Acta 2001, 314, 1-13.

(20) Väyrynen, K.; Hatanpää, T.; Mattinen, M.; Mizohata, K.; Meinander, K.; Räisänen, J.; Link, J.; Stern, R.; Ritala, M.; Leskelä, M. Atomic Layer Deposition of Intermetallic $\mathrm{Co}_{3} \mathrm{Sn}_{2}$ and $\mathrm{Ni}_{3} \mathrm{Sn}_{2}$ Thin Films. Adv. Mater. Interfaces 2019, 6, 1801291.

(21) Väyrynen, K.; Hatanpää, T.; Mattinen, M.; Heikkilä, M. J.; Mizohata, K.; Räisänen, J.; Link, J.; Stern, R.; Ritala, M.; Leskelä, M. Atomic Layer Deposition of Nickel Nitride Thin Films using $\mathrm{NiCl}_{2}$ (TMPDA) and Tert-Butylhydrazine as Precursors. Phys. Status Solidi A 2019, 216, 1900058.

(22) Väyrynen, K.; Hatanpää, T.; Mattinen, M.; Heikkilä, M.; Mizohata, K.; Meinander, K.; Räisänen, J.; Ritala, M.; Leskelä, M. Diamine Adduct of Cobalt(II) Chloride as a Precursor for Atomic Layer Deposition of Stoichiometric Cobalt(II) Oxide and Reduction Thereof to Cobalt Metal Thin Films. Chem. Mater. 2018, 30, 34993507.

(23) Blakeney, K. J.; Winter, C. H. Atomic Layer Deposition of Aluminum Metal Films Using a Thermally Stable Aluminum Hydride Reducing Agent. Chem. Mater. 2018, 30, 1844-1848.

(24) Dey, G.; Elliott, S. D. Copper(I) Carbene Hydride Complexes Acting Both as Reducing Agent and Precursor for Cu ALD: A Study through Density Functional Theory. Theor. Chem. Acc. 2014, 133, 1416 . 
(25) Bowman, W. R.; Krintel, S. L.; Schilling, M. B. Tributylgermanium Hydride as a Replacement for Tributyltin Hydride in Radical Reactions. Org. Biomol. Chem. 2004, 2, 585-592.

(26) Väyrynen, K.; Mizohata, K.; Räisänen, J.; Peeters, D.; Devi, A.; Ritala, M.; Leskelä, M. Low-Temperature Atomic Layer Deposition of Low-Resistivity Copper Thin Films using $\mathrm{Cu}(\mathrm{dmap})_{2}$ and Tertiary Butyl Hydrazine. Chem. Mater. 2017, 29, 6502-6510.

(27) Li, Z.; Rahtu, A.; Gordon, R. G. Atomic Layer Deposition of Ultrathin Copper Metal Films from a Liquid Copper(I) Amidinate Precursor. J. Electrochem. Soc. 2006, 153, C787-C794.

(28) Gadkari, P. R.; Warren, A. P.; Todi, R. M.; Petrova, R. V.; Coffey, K. R. Comparison of the Agglomeration Behavior of Thin Metallic Films on $\mathrm{SiO}_{2}$. J. Vac. Sci. Technol., A 2005, 23, 1152-1161.

(29) Thompson, C. V. Solid-State Dewetting of Thin Films. Annu. Rev. Mater. Res. 2012, 42, 399-434.

(30) Hagen, D. J.; Connolly, J.; Povey, I. M.; Rushworth, S.; Pemble, M. E. Island Coalescence during Film Growth: An Underestimated Limitation of $\mathrm{Cu}$ ALD. Adv. Mater. Interfaces 2017, 4, 1700274.

(31) Lim, J.-W.; Isshiki, M. Electrical Resistivity of $\mathrm{Cu}$ Films Deposited by Ion Beam Deposition: Effects of Grain Size, Impurities, and Morphological Defect. J. Appl. Phys. 2006, 99, 094909. 